\title{
Identifying recommendations to promote remanufacturing in Europe
}

\author{
Iris Karvonen $^{1}$ (D) $\cdot$ Kim Jansson ${ }^{1} \cdot$ Katri Behm $^{1}$ • \\ Saija Vatanen $^{1} \cdot$ David Parker ${ }^{2}$
}

Received: 12 April 2017 / Accepted: 21 July 2017 / Published online: 4 October 2017

(C) Springer Science+Business Media B.V. 2017

\begin{abstract}
According to a recent study conducted by the European Remanufacturing Network project, remanufacturing can contribute significantly to the wellbeing in Europe. The study defined three future scenarios of which the most ambitious transformation scenario foresees the potential to triple the volume of remanufacturing in Europe until 2030 up to about 100 billion Euro employing over half a million people. The transformation, however, will not happen by itself, but important promotion actions need to be taken by various stakeholders, like policy-makers, industrial companies, research and academic community as well as the general public. These stakeholders need to be supported and fed with recommendations to promote remanufacturing in Europe. The paper describes a process applied in the European Remanufacturing Network -project to identify and sort out central barriers that currently prevent large scale capitalisation of remanufacturing potential. The study was based on literature and industrial and expert participation in surveys and workshops. Respectively recommendations to extend remanufacturing were identified and the barriers and recommendations were mapped against each other to assess the sufficiency of the recommendations. After prioritization, finally targeted recommendations for the key stakeholders
\end{abstract}

Iris Karvonen

Iris.Karvonen@vtt.fi

Kim Jansson

Kim.H.Jansson@gmail.com

Katri Behm

Katri.Behm@vtt.fi

Saija Vatanen

Saija.Vatanen@vtt.fi

David Parker

David.Parker@oakdenehollins.com

1 VTT Technical Research Centre of Finland Ltd, P.O. Box 1000, 02044 VTT Espoo, Finland

2 Oakdene Hollins Limited, Ardenham Court, Oxford Road, Aylesbury HP19 8HT, UK 
were defined and reported in this paper: nine for policy makers, four for research \& education, one multi-stakeholder recommendation and seven recommendations for business and industry.

Keywords Recommendations · Barriers for remanufacturing $\cdot$ Stakeholders

\section{Background}

Remanufacturing is an important component of a resource efficient manufacturing industry. Remanufacture involves dismantling a product, restoration and replacement of components and testing of the individual parts and the whole product to ensure that it is within its original design specifications. The performance after remanufacture is expected to be the same as the original performance specification and the remanufactured product generally offers a warranty.

By keeping components and their embodied material in use longer, significant environmental benefits can be realised. Less energy and material resources are used and less waste is being created when the products and components are used again instead of only recycling the materials. Remanufacturing also provides opportunities for the creation of highly skilled jobs and economic growth. Despite these indeed positive features, remanufacturing is an undervalued part of the industrial landscape and an under-recognised industry.

According to a recent study conducted by the European Remanufacturing Network- project [1], remanufacturing in Europe is currently assessed to reach about 30 billion euros. As a comparison, according to a USITC report [2] from 2012, USA is reported as the largest remanufacturer in the world with the value about 43 billion dollars and a growing trend. In order to accelerate the growth in European remanufacturing activities, the European Commission has funded a project to form, coordinate and support a European Remanufacturing Network (ERN). This Horizon 2020 project took place over a period of two years, with the ambition to:

- Encourage new businesses to take up remanufacturing

- Help existing remanufacturers improve their operations

- Improve competitiveness of remanufacturers domestically and internationally

- Create greater awareness of remanufacturing to increase demand and address barriers

\section{Objectives}

One key objective of the ERN project was to provide targeted recommendations to key actors, such as policy makers, product designers and remanufacturing industries, to promote remanufacturing. Specific tasks within this activity involved:

- Consolidation of relevant information from the previous research on barriers for remanufacturing and market knowledge. Translate the identified barriers and identified knowledge gaps as well as development needed into targeted recommendations and future European action planning.

- The recommendations address the different stakeholders individually. The time frame for implementing the recommendations is taken into account in order to have a realistic action plan with the maximum impact by key actors such as European Commission, Governments, industries, policy makers, the research and academic community and society. 
This article describes the main recommendations and the process applied in the ERN project to define them. The main content of the work described consists of analysing the remanufacturing barriers and identifying measures to overcome them.

\section{Research approach}

The methodology for the definition of the recommendations and the action plan is described in Fig. 1. In the used methodology the "The Voice of Industry" is emphasised. The industrial voice comes from more than 600 people through several channels and activities performed in the ERN project, including;

- A Market Study based on an industrial questionnaire with more than 200 industrial responders

- Case Studies. More than 50 industrial companies where interviewed and visited.

- Eight Industrial Workshops in different countries attracted more than 400 participants.

In the used methodology results from previous work in the ERN project were used. The basis for the recommendations identification process is the objective and vision for remanufacturing in Europe which has been set up in the market study performed by the ERN project. The ERN results also included the analysis of remanufacturing business models, processes and design for remanufacturing, using business cases from industry. Additionally literature regarding

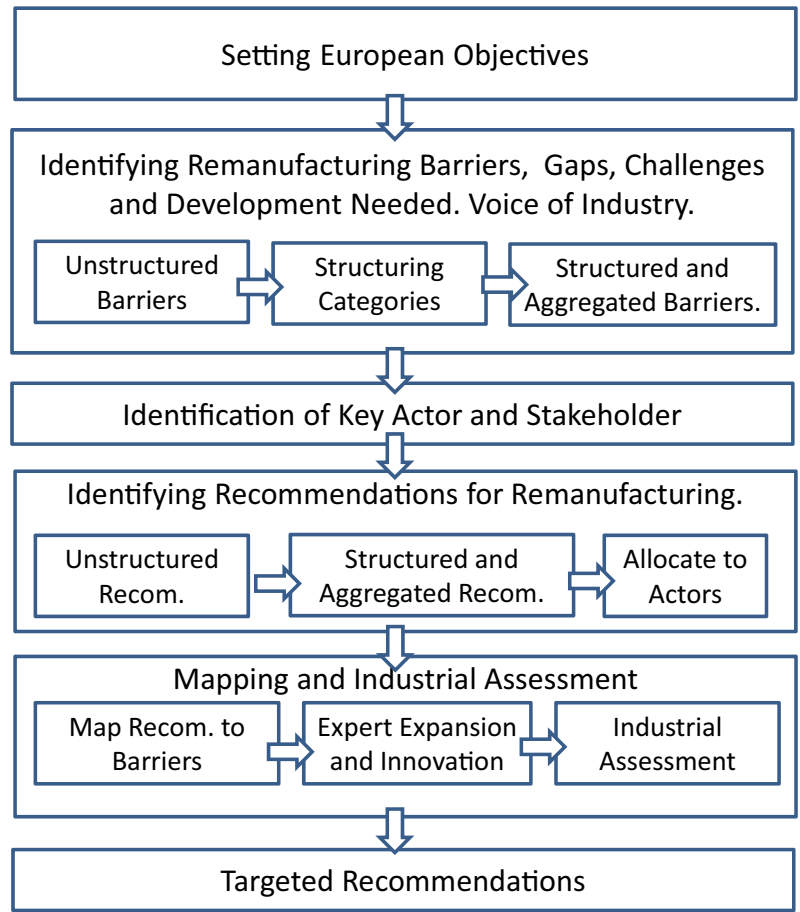

Fig. 1 Methodology for identification of recommendations 
remanufacturing and circular economy was studied. The main information sources are listed in the next sections. The main approach in the identification of recommendations was to study what are the current barriers and challenges of remanufacturing and to define the actions based on them: How the barriers could be overcome, what development actions are needed.

It is also important to understand that in addition to companies active in remanufacturing, other organizations and actors can contribute to the success of remanufacturing. Thus the different stakeholders and key actors were identified.

The consolidation of barriers and recommendations from different sources resulted in two "long lists", one for the identified barriers and another for the identified recommendations. To make the information more usable both of the long lists were analysed to structure them into three categories, dividing the barriers and recommendations accordingly to the key topics of ERN project (business models, design, and processes). Also the overlapping barriers and recommendations in each category were aggregated together to a smaller number; thus making it more easy to assess them.

In each phase the intermediate results were given to the project consortium partners for review, comments, corrections and additions. The final industrial assessment was performed as part of an industrial workshop in Glasgow, September 2016. In the workshop the actions and recommendations were also mapped to the barriers and the timeline and importance of the actions were assessed by the workshop participants. Finally, for each recommendation the targeted stakeholder was identified. In this phase it was found clearer to categorize the recommendations for each stakeholder, instead of the original categorization according to ERN topics. The reorganization also supports dissemination of the recommendations to the target groups. Figure 1 illustrates the methodology for recommendations definition.

The used methodology contains the following steps:

- Setting European industrial objectives for recommendations

The objectives were derived from the ERN project market study. The most ambitious "Transformation" scenario was selected as the basis.

- Identifying remanufacturing barriers, gaps, challenges and development needed.

The step involved the collection of information from literature and from previous ERN results in the field of business models, processes and design. Industrial viewpoints were included from case studies. The resulted "long list" of barriers was analysed, structured and aggregated to the main barriers.

\section{- Identification of Key Actors and Stakeholders}

The stakeholders which could contribute to the adoption of remanufacturing were identified and the key actors were chosen. The recommendations are targeted to these key stakeholders.

- Identifying recommendations for remanufacturing

The step involved the collection of information from previous work and from a large number of other sources and workshops.

Recommendations presented for circular economy in general were reviewed. The high number of derived recommendations was analysed, structured and aggregated for a set which 
could be easier offered for validation and assessment. The aggregated and structured recommendations were allocated to key actors and stakeholders

- Mapping and Industrial Assessment:

The recommendations were mapped to barriers. As a result the recommendations having the highest impact and the barriers having insufficient recommendations were recognized. An industrial workshop was arranged for additional barriers and recommendations. Remanufacturing experts listed recommendations which they considered most important.

The prioritization coming from different assessment methods and sources was consolidated to identify the most important recommendations. Additional recommendations for barriers with missing recommendations were brought in by remanufacturing experts.

- Targeted Recommendations

Summarising and formulation of the final targeted recommendations.

\section{Results}

\section{Objectives and timeline}

In the ERN Remanufacturing Future Market Report (ERN market report) the following scenarios for remanufacturing in Europe in 2030 were defined:

Base case: assumes approximate current growth rates up to 2030 for the remanufacturing intensive industry sectors. An increased understanding of remanufacturing value both from manufacturers and from consumers supports continuing growth resisting some of the downward pressure put on the wider manufacturing industry in Europe. This does not incorporate any step-change in the remanufacturing industry, rather just positive organic growth for the industry. Base Case scenario would yield a production value of $€ 46$ billion, employing some 300,000 people and averting 11 million tonnes of carbon dioxide equivalent. This is a little over a 50\% increase in remanufacturing from today's levels.

Stretch case: a scenario where the value of remanufacturing from the perspectives of creating highly skill jobs and environmental benefits is well understood by policy makers, industry and consumers alike. Remanufacturing is thus incorporated as an important strategy within a wider circular economy. Appropriate policies and promotional activities to foster growth in the remanufacturing industry are adopted resulting in a higher intensity of remanufacturing as a proportion of manufacturing. The Stretch scenario yields more than double today's levels with a value of $€ 73$ billion, employing 450,000 and averting 16 million tonnes of carbon dioxide equivalent.

Transformation case: a scenario where remanufacturing becomes a key strategic pillar for the EU, taking much of the investment and effort away from lower level waste hierarchy activities (Recycle, Recovery and Disposal) and focus on remanufacturing and reuse activities. This would be done based on the belief that remanufacturing and reuse would create significant numbers of highly skilled jobs, ability to avert waste to landfill and associated greenhouse gas emissions. The significant effort results in substantially 
increased intensity of remanufacturing as a proportion of manufacturing by 2030 . In the Transformation scenario by 2030, the value of European remanufacturing would be close to $€ 100$ billion employing over half a million people and averting some 21 million tonnes of carbon dioxide equivalent.

It is assessed that the Base scenario follows the current development, without any additional actions. Thus the recommendations defined in the exercise described aim to exceed the base scenario, up to the Stretch scenario or even the Transformation scenario. The period under review extends to 2030 .

\section{Identifying remanufacturing barriers}

\section{Information sources}

The identification of barriers for Remanufacturing started with the analysis of ERN Project documentation [1], including market analysis and case studies. In the main ERN viewpoints (business models, processes and design) the barriers from each of them were identified. Remanufacturing challenges, obstacles and barriers were also collected from the presentations and discussions in the industrial workshops conducted. In remanufacturing and circular economy literature, there is an abundant supply of different types of remanufacturing challenges, obstacles and difficulties available. However, when collecting this type of information from literature you soon realise that many of the identified barriers are of the same type, thus overlapping to some degree. The sources $[1,3-6]$ have been used.

\section{Industrial voice}

The ERN Market Study was carried out as a questionnaire to industrial recipients, representing companies with some link to remanufacturing. The answers were received from more than 200 industrial partners. The survey included the question: "How important are the following barriers for remanufacturing to your company? (1=Not important, 4=Very important)". Figure 2 shows the industrial view of importance of remanufacturing barriers as percentage of respondents. It can be

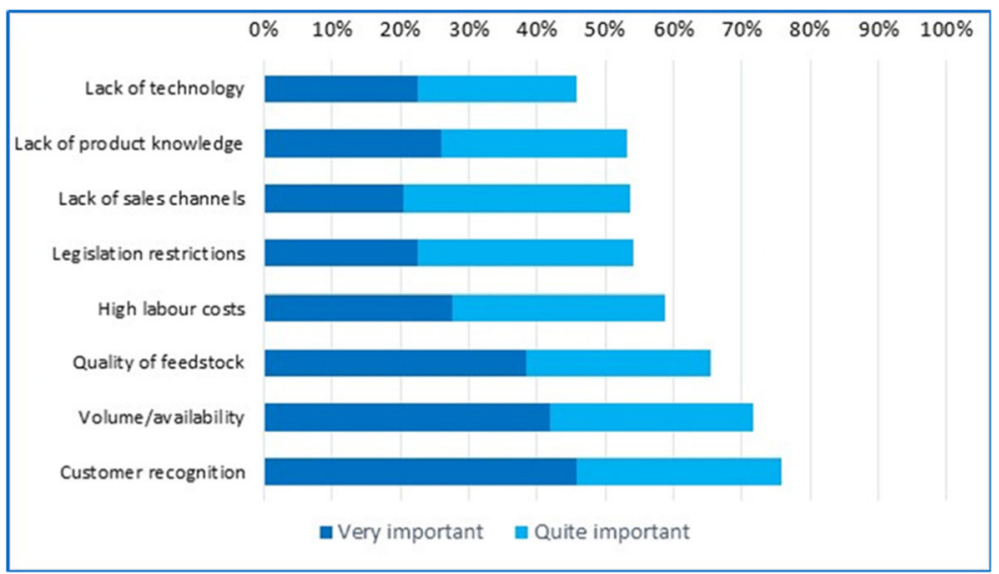

Fig. 2 Importance of remanufacturing barriers in ERN market study 
seen that the core volume, availability and quality were found very or quite important for most of the respondents. Also the customer recognition was seen as of high importance.

\section{Identified unstructured remanufacturing barriers}

Analysing the information sources from previous research and from ERN results generated an unstructured list of almost 300 barriers which were partly overlapping and at different levels of detail. The large number and different levels of expression made the list difficult to manage. Thus the information had to be structured and reduced to a more manageable list. For the purpose a categorization according to viewpoints used in ERN was applied, namely Business Models, Design for Remanufacturing and Remanufacturing Process. The three categories where further structured into subcategories. Table 1 shows the structuring scheme that was used.

\section{Organizing barriers to structures}

For the practical structuration, a MS Excel-tool @ was used to manage all the original barriers, to keep up their sources and to perform the organizing into selected structures. Mainly it was quite straightforward to place the barriers into the structure but in some cases a barrier was set in two different groups. Details of the distribution of barriers can be seen in Fig. 3 below. It should be noted that the numbers do not directly express the importance of each barrier. Partly this is because the originally listed barriers were at different levels of scope and detail. Also, for example the lower number of barriers for Design for Remanufacturing (DfRem in the figure) is coming mainly from the novelty of this subject. A reason why more product types are not remanufactured is that their design does not facilitate remanufacturing [7]. In addition, the design problems are likely to be more severe for

Table 1 Structuring scheme for remanufacturing barriers

\begin{tabular}{ll}
\hline Business model & Need for capital investment \\
Definition of remanufacturing \\
Intellectual property and knowledge issues \\
Consumer awareness and perception, \\
remanufacturing reputation \\
Institutional barriers \\
Liability, regulations, legislation, standards \\
Low cost competition \\
Reman costs, competitiveness \\
Market size, marketing, cannibalising \\
primary markets \\
Demand for remanufacturable products \\
OEM investment in remanufacturing \\
Knowledge of DfRem principles \\
Integration of end-of-life learning into \\
product design \\
Lack of control of core collection, \\
reverse logistics, quality of cores \\
Availability of spare parts \\
Increasing technological complexity, \\
new technology and innovations, \\
more electronics \\
Skills, infrastructure, capacity \\
Process efficiency and flexibility \\
\\
\end{tabular}


independent remanufacturers that do not have the full product knowledge and needs to perform much reverse engineering in order to understand how to perform a proper remanufacturing of the product.

\section{Aggregation of barriers}

After the barriers were put into their categories the number was reduced, by removing overlaps, merging and reformulating barriers with nearly similar content. Some generalization was also made. By doing this the reference to the original source was lost. After the aggregation process the nearly 300 barriers were transformed into a list of 74 structured remanufacturing barriers.

\section{Identification of key actors and stakeholders}

Remanufacturing requires many different competences and capabilities. Thus, collaboration between different companies along the supply chain is typically needed to perform remanufacturing processes. There are different collaboration forms, depending on the remanufacturing "network manager" (OEM, contracted, independent), product type, location etc. To progress in remanufacturing, however, not only the companies already active in manufacturing and remanufacturing are needed. The whole product lifecycle should be involved, thus taking remanufacturing option into account in product design, sales and lifecycle services (including end of life). By doing so, information about the product being remanufactured can be shared instead of getting lost along the way and reverse engineered at the remanufacturing stage, see [8]. The role of government regulation is often mentioned in Circular economy literature, but also different types of support organizations (like industry associations, research \& education), even different communities can influence the future development.

In many business fields the role and activity of customers is increasing and companies need to be more aware of customer needs and preferences. The customers may be either enterprises or consumers. Perhaps remanufacturing could be increased through better customer awareness and

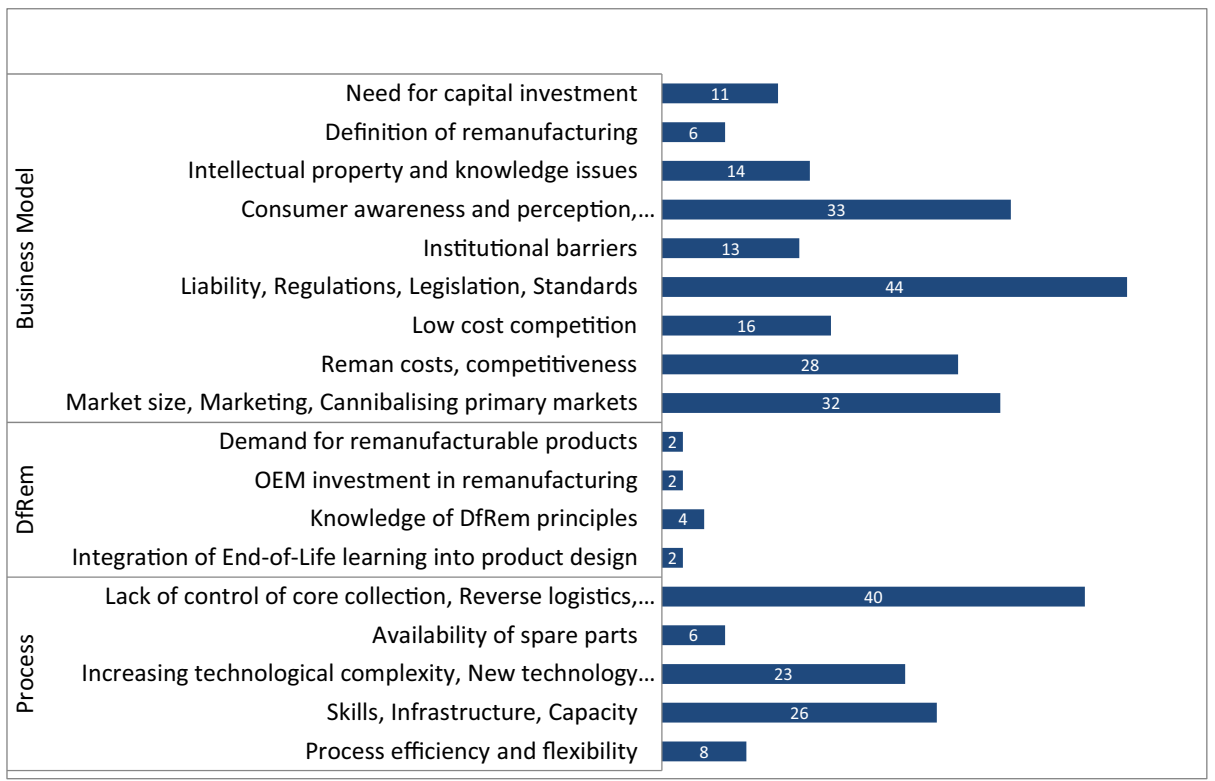

Fig. 3 Number of barriers per category 
participation. The customers are strongly influenced by the general opinion at each point of time. This should also be taken into account.

Four categories of Key Actors in remanufacturing were selected and agreed on in the ERN project. The grouping presented in Table 2 was used. The main categories of Key Actors have been further structured into more detailed subcategories.

\section{Identified recommendations}

For the first identification of unstructured recommendations for remanufacturing, an analogous process as in the identification of barriers was used: first the "long list" of recommendations was identified using different sources, then their categories were identified and finally they were aggregated into the categories according to ERN topics (business models, process, design).

\section{Information sources}

The ERN Project documentation has been used as the first sources of information. There is also a wealth of literature on different recommendations for Remanufacturing and circular economy in general. The sources [7-20] listed in the References section have been used.

Table 2 Key actors in remanufacturing

\begin{tabular}{|c|c|}
\hline $\begin{array}{l}\text { Business enterprises } \\
\text { and industries }\end{array}$ & $\begin{array}{l}\text { Original Equipment Manufacturer (OEM) } \\
\text { Original Equipment Remanufacturer (OER) } \\
\text { Contracted remanufacturers (CR) } \\
\text { Independent remanufacturers (IR) } \\
\text { Reman specific service providers; cleaners, } \\
\quad \text { disassemblers, testers etc. } \\
\text { Logistics providers; transport and storage } \\
\text { Core collectors and sorters } \\
\text { Maintenance partners } \\
\text { Spare part providers } \\
\text { Disassemblers and scrap collectors } \\
\text { Reman products sales partners, } \\
\quad \text { marketplaces } \\
\text { Recycling companies } \\
\text { Finance }\end{array}$ \\
\hline Policy makers & $\begin{array}{l}\text { European Commission } \\
\text { Governments, } \\
\text { Authorities } \\
\text { Standardisation bodies } \\
\text { Conseil Européen de Remanufacture (CER) } \\
\text { Industrial associations } \\
\text { Lobbying organizations } \\
\text { Consultants }\end{array}$ \\
\hline $\begin{array}{l}\text { The research and } \\
\text { academic community }\end{array}$ & $\begin{array}{l}\text { Research Centres } \\
\text { Research funding organizations } \\
\text { Universities and Polytechnics } \\
\text { Private education and training } \\
\text { European Remanufacturing Network (ERN) }\end{array}$ \\
\hline General public & $\begin{array}{l}\text { General public } \\
\text { Media } \\
\text { Culture } \\
\text { Other }\end{array}$ \\
\hline
\end{tabular}




\section{Identified unstructured remanufacturing recommendations}

Analysing information sources resulted in an unstructured list of 120 recommendations. As for barriers, the information had to be structured and reduced to a more manageable list.

\section{Structuration and aggregation}

In the first phase the same structure scheme as for barriers was used, namely the categories; Business Models, Design for remanufacturing and Process. In addition to the ERN three main structures, a fourth category "Other" was added for recommendations that are more general or do not otherwise fit within the ERN categories. Also the same methodology and tools as for barriers were used to structure the recommendations. In some cases the text describing and motivating the recommendation was quite long. A laborious task was undertaken to remove overlapping recommendations and to aggregate and merge them into a more manageable list. During the aggregation process also each recommendation was mapped to one or several actors. The list of key actors was used. After the aggregation process a more manageable structured list of 67 recommendations for remanufacturing was reached. Figure 4 shows the distribution of recommendations per Actor.

\section{Organizing aggregated recommendation to structures}

The MS Excel-tool ${ }^{\circledR}$ as mentioned in "Identifying remanufacturing barriers" section was used to analyse how the aggregated recommendations fall into the used structure (business model, processes and design). Details of the distribution of recommendations can be seen in Fig. 5 below. Even if the numbers indicate which areas have been highlighted in the source material, they do not directly tell the importance of each aggregated recommendation. One reason is again the different level of scope and detail of different recommendations.

\section{Analysing aggregated recommendation and actors}

A further analysis was conducted to check if a specific group of Actors can be seen as responsible for certain categories of recommendations. Figure 6 shows the number of recommendations per actor and

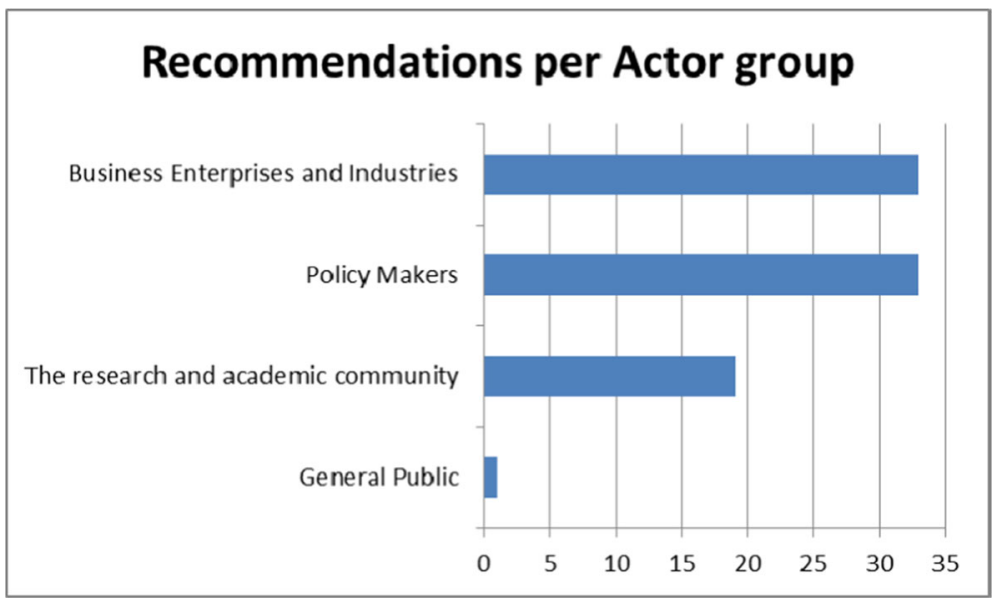

Fig. 4 Number of recommendations per actor group 
category (Business Model, DfRem and Process). From the graph it can be seen that the actor group Business Enterprises and Industries are seen as responsible for developing remanufacturing processes, while Policy Makers are seen as responsible for developing the business opportunities for remanufacturing. However the distinction is not very clear.

\section{Mapping and industrial assessment of recommendations}

Three different methods for selecting the most important recommendations were used.

1. Desktop analysis. Combining and cross checking recommendations and barriers.

2. Industrial assessment done in workshops

3. A collection of ERN expert opinions and ratings of the most important recommendations. The ERN experts also contributed with their knowledge for additional recommendations for barriers with missing recommendations.

As a final step the three approaches were combined to identify the main targeted recommendations.

\section{Desktop analysis}

The result from Fig. 3 (number of barriers per ERN grouping category) and Fig. 6 (number of recommendations per ERN grouping category) were compared. A fairy good correlation between the two data sets could be noticed. The areas perceived as problematic, with many barriers, also received attention in the form of a large number of recommendations. The conclusion is that the structure of categories was well chosen.

A further analysis was done by mapping recommendations to barriers, which barrier is removed with which recommendation or action. The analysis may give two kinds of useful information: 1)

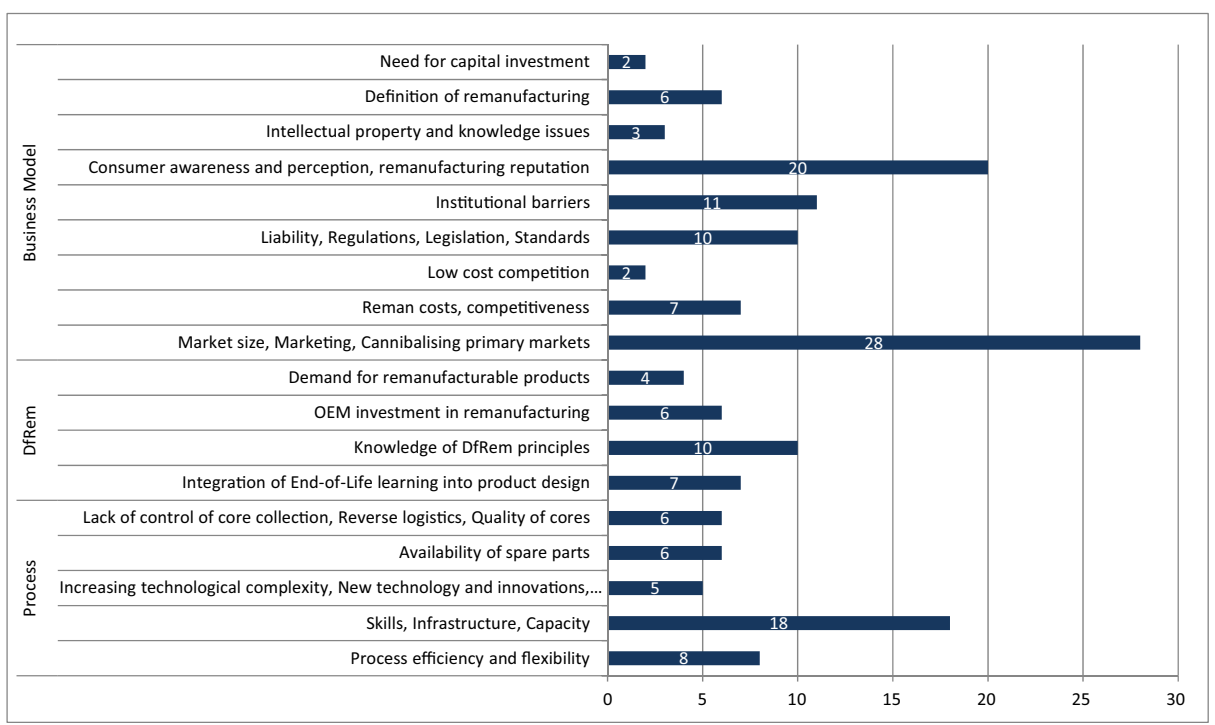

Fig. 5 Number of recommendations per category 


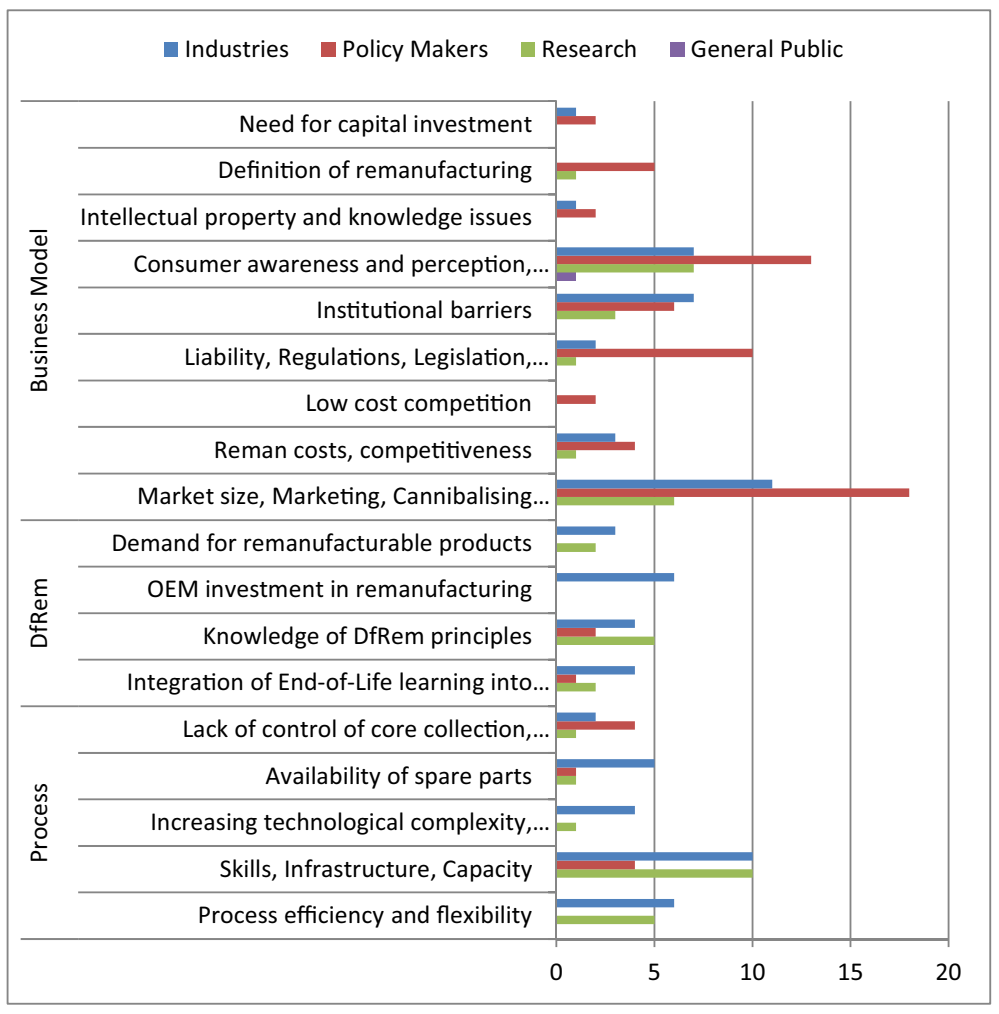

Fig. 6 Number of recommendations per actor group and category

which recommendations decrease or remove many different barriers? These actions may have high impacts. 2) which barriers miss any recommendation/ action? What additional actions are needed and could help?

Even after the structuring and aggregation the number of barriers (74) and recommendations (67) was quite high to compare each individual recommendation to each barrier. Thus the first approach was to perform the mapping inside the categories: business model, design and processes. This means that the recommendations related to business models were compared with the barriers related to business models, etc. Soon after starting the analysis it was found that this kind of analysis alone does not give the correct view on the impact of the actions on the barriers. Clearly some recommendations could affect different types of barriers. Thus it was decided not to restrict the desktop mapping inside the categories but to cross check also between the other categories. In the analysis all the structured recommendations were reviewed to identify the barriers they affect. As a whole, about 100 links were identified of which about one fourth were across the three categories: for example, some recommendations relating to barriers related to business models also influence on barriers related to processes.

The graph in Fig. 7 shows the "top" recommendations based on number of linked barriers. This means that each of these recommendations helps to overcome several barriers. The listed recommendations remove or decrease at least 3 different barriers.

Another objective was to identify barriers for which there were not sufficient recommendations. Based on the analysis three potentially missing subjects were identified. Firstly, there are tensions and insufficient collaboration between OEMs and third party remanufacturers. Secondly, safety \& security in remanufacturing needs to be ensured. And thirdly, there are insufficient resources for 
remanufacturing. To tackle these barriers, ERN experts contributed with their knowledge for additional recommendations for these barriers with missing recommendations. Thus, to remove tensions and to improve collaboration between OEMs and third party remanufacturers, Business Enterprises and Industries are recommended to collaborate in design, manufacturing and remanufacturing to create sustainable solutions. To improve resources for remanufacturing, Educators and Researchers should improve cross-disciplinary teaching and education for remanufacturing and help business to incorporate remanufacturing. In addition, Business Enterprises and Industries should stimulate investment in remanufacturing industry by promotion to third party investors. Unfortunately no recommendations were found to ensure safety and security in remanufacturing, so this barrier would need to be considered further in some other projects.

\section{Industrial recommendations assessment workshop}

An industrial workshop was arranged for the assessment purpose. It was attended by about 25 representatives from industry and research community. The participants were asked to review the identified barriers and recommendations in groups of 4-5 persons. As a result the workshop formulated, in all, ten new recommendations. In addition, each working group indicated the five most important recommendations from the aggregated list of recommendations. The new recommendations were compared with the list of structured recommendations. A correspondence was found for most of the given recommendations.

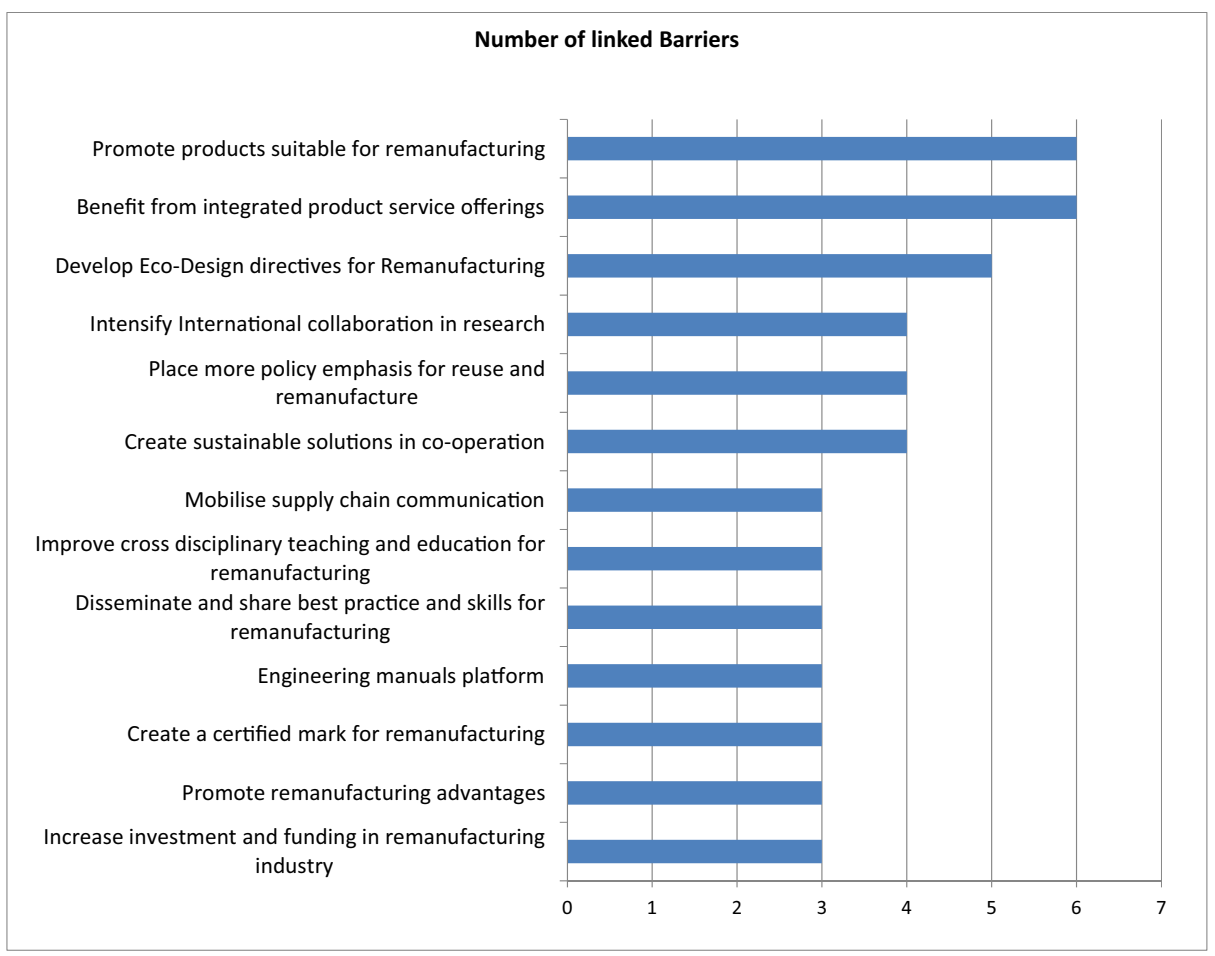

Fig. 7 List of recommendations influencing at least 3 barriers 


\section{Expert opinions and ratings of the most important recommendations}

The ERN experts were asked to select at most ten key recommendations to mitigate barriers for remanufacturing in Europe. The partners were also asked to place the recommendation with the highest priority at the top. The answers were collected from all partners. The following graph, Fig. 8 , shows the recommendations receiving the most attention (at least 3 persons have selected the recommendation in their list of ten key representations). Additionally the graph shows the cumulative priority presented as the sum of the priorities given by partners. From the graph it can be concluded that there is a fairly good correspondence between the number of supporting persons and cumulative priority. The most important recommendation was found to be the removal of the

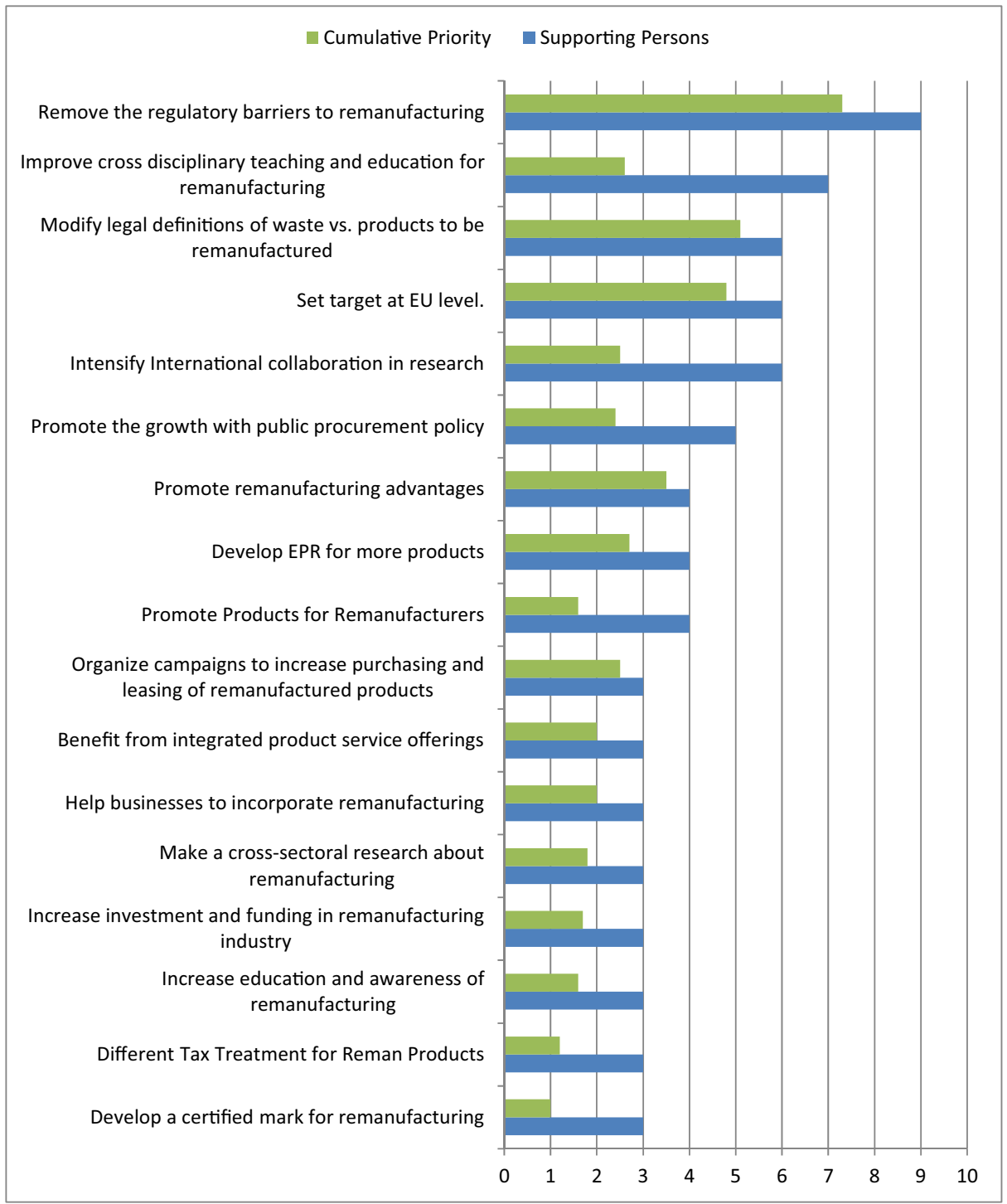

Fig. 8 Recommendations selected by persons at ERN partners 
regulatory barriers to remanufacturing and in the next the focus was on teaching and education for remanufacturing. Also international collaborative research for remanufacturing was seen important. The ERN experts mainly come from research which influenced the high popularity of education and research. On the other hand, in this prioritization, the recommendations targeted against industry were not that visible.

\section{Combining three approaches}

The three approaches (desktop analysis of identifying and structuring the barriers and recommendations; industrial assessment done in the workshops; and the collection of ERN partners' opinions) were combined to finally select the most important recommendations. In order to combine the three views the recommendations were put into a common table, Table 3. The table contains the recommendations influencing at least three barriers, recommendations selected by the industrial workshop and recommendations selected by at least three experts.

It can be seen that 5 recommendations were supported by all the 3 approaches: increasing investment, promoting remanufacturing advantages, benefitting from integrated service offerings, improving cross-disciplinary education, and promoting products suitable for remanufacturing. 8 recommendations were supported by 2 approaches: creating a certification mark, mobilising supply chain communications, raising the policy profile of remanufacturing, boosting international research and education, promoting leasing as an enabler, developing extended producer responsibility, and directly assisting businesses to incorporate remanufacturing.

It should be noted, though, that this list represents a mixture of issues, actions and potential desired outcomes. The challenge is to unpick these into underlying issues which can then be attributed with specific actions and - importantly - sponsors who will take up these actions, believing them to be both practical and valuable. That is the subject of the next section.

\section{Targeted recommendations}

The previous sections have described the process of discovering and clustering the main issues, concerns, desired outcomes and potential actions. In the definition of targeted stakeholders for each recommendation it was identified that the previously used categorization (recommendations related to business models, processes, design) was not essential from the stakeholder point of view. Thus to achieve a compact and understandable presentation of recommendations the categorization was transformed to the targeted stakeholder types (regulation, academy \& research, industry, general public). Most of the recommendations could be clearly targeted to a specific stakeholder group but some (like increasing the awareness about remanufacturing) were related to several stakeholder types.

The analysis has tried to include the views of different practitioners in different sectors. It is important to recognise that - because of the availability of representatives - not all such views have necessarily been accommodated; and, even if they have been, there will be notable differences in preference between independent remanufacturers and OEMs and so on. In addition, the eventual end markets for remanufactured goods - be they business, public sector or consumers - also operate with different mind-sets, openness to the possibilities of remanufacture are more or less well-functioning in the economic sense. Recommendations may therefore not apply equally across all products and markets. As a 
Table 3 Recommendations getting most support by three approaches

\begin{tabular}{llll}
\hline Remanufacturing recommendations & $\begin{array}{l}\text { Cross checking } \\
\text { recommendations } \\
\text { and barriers }\end{array}$ & $\begin{array}{l}\text { Industrial } \\
\text { Workshop }\end{array}$ & $\begin{array}{l}\text { ERN Experts' } \\
\text { rating }\end{array}$ \\
\hline
\end{tabular}

Short name

Increase investment and funding in remanufacturing industry

Promote remanufacturing advantages

Benefit from integrated product service offerings

Promote products suitable for remanufacturing

Improve cross disciplinary teaching and education for

Create a certified mark for remanufacturing

Mobilise supply chain communication

Place more policy emphasis for reuse and remanufacture

Intensify International collaboration in research

Organize campaigns to increase purchasing and leasing of

Increase education and awareness of remanufacturing

Develop extended producer responsibility for returning products

Help businesses to incorporate remanufacturing

Create sustainable solutions in co-operation

Develop Eco-Design directives for Remanufacturing

Engineering manuals platform

Disseminate and share best practice and skills for

Integration of Contract remanufacturers in DfRem

Publish DfREM success stories

Develop DfRem guidelines

Improve DfRem knowledge

DfRem tool

Develop online platforms for core exchange

Increase international access to used products

Improve and incentivise collecting used items

Establish a forum to share best practice

Improve availability of spare parts for independent

Provide remanufacturing services

Research into advanced materials repair technology

Highlight key issues within the industry

Research into advanced material repair technology

World-wide reman standards

Modify legal definitions of waste vs. products to be

Make a cross-sectoral research about remanufacturing

$\begin{array}{lll}\mathrm{x} & \mathrm{x} & \mathrm{x} \\ \mathrm{x} & \mathrm{x} & \mathrm{x} \\ \mathrm{x} & \mathrm{x} & \mathrm{x} \\ \mathrm{x} & \mathrm{x} & \mathrm{x} \\ \mathrm{x} & \mathrm{x} & \mathrm{x} \\ \mathrm{x} & \mathrm{x} & \\ \mathrm{x} & \mathrm{x} & \\ \mathrm{x} & \mathrm{x} & \\ & & \mathrm{x} \\ & \mathrm{x} & \mathrm{x} \\ & \mathrm{x} & \mathrm{x} \\ & \mathrm{x} & \mathrm{x} \\ & \mathrm{x} & \mathrm{x}\end{array}$

Set target at EU level.

Develop a certified mark for remanufacturing

Remove the regulatory barriers to remanufacturing

Differentiate the taxes for remanufacturers

$\mathrm{X}$

consequence, we have attempted to distil from the candidate 'issues' those which can have a broad applicability, and caveat where the approach may have an impact limited to specific circumstances.

Taking these factors into account, further refinement of the candidate recommendations has been necessary. The recommendations presented below represent this combination of 
practicality, impact and potential attribution to specific actors who will own and execute them. In the following sections, Tables 4, 5, 6, and 7, the targeted recommendations are listed briefly. It is out of the scope of this paper to go into details regarding the recommendations, their implementation timeframe and priorities. More details can be found in [1].

\section{Recommendations for policymakers}

The recommendations for policy makers (Table 4) aim to identify how policy could support the enhancement of remanufacturing in Europe. In the background there are for example the trade barriers which limit the potential for remanufacturing being able to globally move goods when supply and demand are not in the same country. To progress in this area, identification of the relevant regulation and how it could be modified, is needed. Different means to support remanufacturing, like financial incentives and public procurement can be used. The general shortage of awareness is proposed to be decreased by the clarification of the definitions of waste and remanufacturing.

\section{Recommendations for educators and researchers}

Cross-disciplinary education about remanufacturing is needed (Table 5): not only technical issues, but also design, process management (including reverse logistics) and business models and management. Especially for the design new approaches and design tools are needed. Thus collaborative, cross-disciplinary research is needed. The recommendation could be elicited further to define a scheme for remanufacturing education and a roadmap for multi-disciplinary remanufacturing research activities.

Table 4 Targeted recommendations for policymakers

\begin{tabular}{|c|c|}
\hline Issue & Action \\
\hline \multicolumn{2}{|c|}{ Set ambition, targets and measurement systems for effective remanufacturing CE policy } \\
\hline \multirow[t]{2}{*}{$\begin{array}{l}\text { Remanufacturing is not a targeted element } \\
\text { of the Circular Economy within the EU. }\end{array}$} & $\begin{array}{l}\text { Set an escalating target for remanufacturing } \\
\text { activity at EU level. }\end{array}$ \\
\hline & $\begin{array}{l}\text { Collect structured economic data on European } \\
\text { remanufacturing. }\end{array}$ \\
\hline \multicolumn{2}{|c|}{ Ensure a consistent EU fiscal and regulatory regime is in place } \\
\hline \multirow{3}{*}{$\begin{array}{l}\text { Remanufactured products and processes } \\
\text { do not enjoy the same financial } \\
\text { incentives }\end{array}$} & $\begin{array}{l}\text { Create financial incentives which support } \\
\text { remanufacturing. }\end{array}$ \\
\hline & $\begin{array}{l}\text { Clarify legal definitions of waste vs. products } \\
\text { to be remanufactured. }\end{array}$ \\
\hline & $\begin{array}{l}\text { Develop extended producer responsibility to } \\
\text { strengthen take-back obligations for products. }\end{array}$ \\
\hline \multicolumn{2}{|l|}{ Tackling international trade issues } \\
\hline \multirow{2}{*}{$\begin{array}{l}\text { Internationalisation of remanufacturing } \\
\text { is being hampered by different national } \\
\text { policies, tariff barriers, standards } \\
\text { and definitions. }\end{array}$} & $\begin{array}{l}\text { Clarify and disseminate international definition } \\
\text { on remanufacturing and related standards. }\end{array}$ \\
\hline & $\begin{array}{l}\text { Identify and remove the regulatory } \\
\text { barriers to remanufacturing. }\end{array}$ \\
\hline \multicolumn{2}{|c|}{ Improving awareness of and confidence in remanufactured goods } \\
\hline \multirow{2}{*}{$\begin{array}{l}\text { Awareness of and confidence in remanufactured } \\
\text { products amongst public and domestic } \\
\text { purchasers is low. }\end{array}$} & $\begin{array}{l}\text { Promote remanufacturing through public } \\
\text { procurement policy. }\end{array}$ \\
\hline & $\begin{array}{l}\text { Create a certified mark for remanufacturing } \\
\text { and clarify liabilities }\end{array}$ \\
\hline
\end{tabular}


Table 5 Targeted recommendations for educators and researchers

\begin{tabular}{|c|c|}
\hline Issue & Action \\
\hline \multicolumn{2}{|l|}{ Future business leaders' skills agenda } \\
\hline $\begin{array}{l}\text { Future business leaders, product designers } \\
\text { and process operators are not well supplied } \\
\text { by conventional training courses. }\end{array}$ & $\begin{array}{l}\text { Boost cross-disciplinary teaching and education in } \\
\text { remanufacturing. }\end{array}$ \\
\hline \multicolumn{2}{|l|}{ Current remanufacturing base skills agenda } \\
\hline $\begin{array}{l}\text { Existing remanufacturers and potential new } \\
\text { ones lack capacity or knowledge to grow } \\
\text { and adapt their business models } \\
\text { and practices. }\end{array}$ & $\begin{array}{l}\text { Develop learning materials and tools to assist } \\
\text { current, growing remanufacturers and those } \\
\text { wishing to diversify into remanufacturing. }\end{array}$ \\
\hline \multicolumn{2}{|l|}{ Advancing remanufacturing state of the art } \\
\hline $\begin{array}{l}\text { Lack of an international research agenda is } \\
\text { hampering the spread and advancement }\end{array}$ & $\begin{array}{l}\text { Increase research and international collaboration } \\
\text { to promote remanufacturing. }\end{array}$ \\
\hline of remanufacturing state of the art. & $\begin{array}{l}\text { Develop an integrated set of design tools and } \\
\text { evaluation techniques that can support business } \\
\text { model, product and process design. }\end{array}$ \\
\hline
\end{tabular}

\section{Recommendations for multi-stakeholders}

One of the objectives of ERN project was to establish European network of actors in the remanufacturing field to promote and collaborate in remanufacturing (Table 6).

\section{Actions for business and industry}

The business and industry constitute a group of different kinds of companies which can operate in different roles in the remanufacturing network or companies that are not yet active in remanufacturing. The group involves different types of remanufacturers: Original Equipment Remanufacturers (OER), Contracted remanufacturers (CR) and Independent remanufacturers (IR). Additionally companies are needed for remanufacturing specific service; cleaners, disassemblers, testers, logistics providers; transport and storage, core dealers, brokers, collectors and sorters and maintenance partners and spare part providers, disassemblers and scrap collectors. Also recycling companies and Original Equipment Manufacturers (OEM) not yet performing remanufacturing can be the target for industrial recommendations. The companies may operate in different industrial fields and they may be of different sizes.

Thus, because of the high diversity, it is impossible to recommend very detailed and specific actions for the industry, but they need to be given at a proportionally high level. The suitability of each recommendation for a specific company depends largely on the business situation, for example, if it is beneficial and potential to move from product offering to service offering, thus allowing easier return of cores. On the other hand the recommendation

Table 6 Targeted recommendations for multi-stakeholders

\begin{tabular}{ll}
\hline Issue & Action \\
\hline $\begin{array}{l}\text { European remanufacturing centre of excellence } \\
\begin{array}{l}\text { Provide a technology research platform capable of supporting } \\
\text { sector level collaborative research. }\end{array}\end{array}$ & $\begin{array}{c}\text { Establish a European Remanufacturing } \\
\text { Centre of Excellence }\end{array}$ \\
\hline
\end{tabular}


Table 7 Recommendations for business and industry

\begin{tabular}{|c|c|}
\hline Issue & Action \\
\hline \multicolumn{2}{|l|}{ Actions requiring remanufacturers or sector bodies to initiate } \\
\hline $\begin{array}{l}\text { Conventional business models and processes } \\
\text { are not supportive of remanufacturing for } \\
\text { a wide range of products. }\end{array}$ & $\begin{array}{l}\text { Remanufacturers should consider integrated } \\
\text { product-service based offerings as an } \\
\text { alternative to make/sell models. }\end{array}$ \\
\hline $\begin{array}{l}\text { Design for Remanufacture is not a standard } \\
\text { component of the design process }\end{array}$ & $\begin{array}{l}\text { Design and promote products suitable for } \\
\text { remanufacturing. }\end{array}$ \\
\hline $\begin{array}{l}\text { OEM and third party remanufacturers may } \\
\text { have conflicting business interests }\end{array}$ & $\begin{array}{l}\text { Collaborate along the supply chain to create } \\
\text { sustainable product solutions. }\end{array}$ \\
\hline \multicolumn{2}{|l|}{ Actions requiring multiple parties to collaborate } \\
\hline $\begin{array}{l}\text { Core return for } \mathrm{B} 2 \mathrm{C} \text { goods is poor, often resulting } \\
\text { in unusable, low quality items unfit for } \\
\text { remanufacture. }\end{array}$ & $\begin{array}{l}\text { Encourage measures which increase the } \\
\text { transparency and value of options } \\
\text { available to consumers, users etc. at end } \\
\text { of life to improve circularity. }\end{array}$ \\
\hline $\begin{array}{l}\text { Low awareness of remanufacturing as part } \\
\text { of the Circular Economy }\end{array}$ & $\begin{array}{l}\text { Promote remanufacturing advantages } \\
\text { to potential purchasers. }\end{array}$ \\
\hline \multicolumn{2}{|l|}{ Actions where the main agent has not been identified yet } \\
\hline $\begin{array}{l}\text { Lack of familiarity with remanufacturing in the } \\
\text { finance sector can make it difficult for } \\
\text { remanufacturers to access capital }\end{array}$ & $\begin{array}{l}\text { Promote remanufacturing advantages } \\
\text { to financial institutions. }\end{array}$ \\
\hline
\end{tabular}

relating to collaboration in the supply chain could be relevant to any company, even if the collaboration could be different in different cases. Thus, as a conclusion, the recommendations for industry (Table 7) can be seen as a generic advice. To build more specific guidelines the generic recommendations should be analysed and turned to the situation of the specific company. Performing this in a number of cases would further validate also the generic recommendations.

\section{Conclusions}

In order to promote remanufacturing activities in Europe, the European Commission funded the European Remanufacturing Network project. The project performed a market study in which the proportion of manufactured output that achieves an extended life through remanufacturing (remanufacturing intensity) was identified as a mere 2\%. Also future scenarios by 2030 were defined. The most ambitious transformation scenario foresees the potential to triple the volume of remanufacturing in Europe until 2030 up to about 100 billion euros.

This paper aims to support the transformation scenario by defining recommendations to overcome the remanufacturing barriers. The barriers for remanufacturing processes, business models and design for remanufacturing were identified based on literature and inclusion of industrial opinions. The recommendations to different stakeholders, including policy making, research \& education and industry and general public, were correspondingly studied. The described analysis tried to be as inclusive as possible of the views of different practitioners in different sectors. The analysis resulted in about 300 partly overlapping both for barriers and about 120 recommendations. Thus to report them, structuring, aggregation and prioritization were needed. The paper describes the process of discovering and clustering the main issues, concerns, desired outcomes and potential actions. As a result, nine main recommendations were defined for policy 
makers, four for research \& education, one multi-stakeholder recommendation and seven main recommendations for business and industry.

As a result of the aggregation, some of the recommendations are still quite generic. Thus, to implement them in the future they should be further analyzed and concretized. For example, the regulations currently impeding remanufacturing should be further studied and the regulatory changes needed should be detailed. For remanufacturing education and research the needed knowledge and curricula as well as a research roadmap should be further defined. The suitability of the recommendations to industry should be analyzed and validated in different sectors, company sizes and business environments and turned into more concrete guidelines for specific types of companies or specific companies.

CE, Circular Economy; CER Conseil Européen de Remanufacture; CR, Contracted Remanufacturer; DfRem, Design for Remanufacturing; ERN, European Remanufacturing Network; IR, Independent Remanufacturer; OEM, Original Equipment Manufacturer; OER, Original Equipment Remanufacturer.

Acknowledgements This work was partly funded by the European Commission through the Project ERN: "The European Remanufacturing Network - Coordinating and Supporting European Remanufacturers", Grant agreement no: 645984 .

Authors' contributions All authors at VTT have participated in the information collection, identification of barriers and recommendations. KJ has developed and used the analysis methodology. KB has refined the structured list of recommendations. IK has performed the consolidation and mapping of barriers to recommendations. All authors have contributed to the industrial assessment and workshops. DP has contributed to the formulation of the final recommendations as responses to issues encountered.

\section{Compliance with ethical standards}

Competing interests The authors declare that they have no competing interests.

Authors' information IK works as a principal scientist at VTT Technical Research Centre of Finland in a team focusing on 'Business renewal in organizations and networks'. Her main research areas are collaboration networks, product life cycle services, sustainable manufacturing and risk management in enterprise networks. $\mathrm{KJ}$ is currently working as a senior scientist at VTT in a team focusing on 'Business Eco-system Development'. His main research areas are collaboration networks in manufacturing and engineering, product life cycle services, remanufacturing and information systems in marine engineering. KB and SV are working as a research scientist and a senior scientist, respectively, at VTT in a team focusing on sustainability assessment of industrial products. They have carried out several life cycle assessment and recyclability studies, mainly on the manufacturing industry. DP is a specialist in Circular Economy at the Centre for Remanufacturing \& Reuse. His project work included evaluating new technologies for reducing resource use and research into effective waste prevention strategies.

\section{References}

1. The European Remanufacturing Network: [https://www.remanufacturing.eu/]. Accessed 16 March 2017

2. USITC (2012) Remanufactured goods: an overview of the US and Global Markets and Trade 2012

3. Karvonen I, Jansson K; Vatanen S, Tonteri H, Uoti M, Wessman-Jääskeläinen H (2015) Uudelleenvalmistus osana kiertotaloutta. Espoo, VTT. VTT Technology; 207. DemaNet report in Finnish. ISBN 978-951-38-8210-5; 978-951-38-8211-2. Accessible from: http://www.vtt. fi/inf/pdf/technology/2015/T207.pdf

4. Kok L, Wurpel G, Ten Wolde A (2013) Unleashing the power of the circular economy. Report by IMSA Amsterdam for Circle Economy. Accessible from: www.imsa.nl and http://www. circle-economy.com. 16 Aug 2016 
5. Benoy A-M, Owen L, Folkerson M (2014) Triple Win-the social economic and environmental case for remanufacturing. All-Party Parliamentary Sustainable Resource Group (APSRG) and AllParty Parliamentary Manufacturing Group (APMG), London. Accessible from: http://www. policyconnect.org.uk/apsrg/sites/site_apsrg/files/report/535/fieldreportdownload/triplewinthesocialeconomicandenvironmentalcaseforremanufacturing.pdf. 16 Aug 2016

6. Walsh B, Waugh R, Symington H (2015) Circular economy evidence building programme. Remanufacturing study. Zero waste Scotland. Accessible from: zerowastescotland.org.uk. 5 June 17

7. Sundin E (2004) Product and process design for successful remanufacturing, Linköping Studies in Science and Technology, Dissertation No. 906, Department of Mechanical Engineering, Linköping University, SE58183 Linköping, Sweden

8. Kurilova-Palisaitiene J, Lindkvist L, Sundin E (2015) Towards facilitating circular product life-cycle information flow via remanufacturing, The 22nd CIRP Conference on Life-Cycle Engineering, Sydney, Australia, April 7-9, Procedia CIRP, Volume 29, 2015, p 780-785

9. Boland D, Bastein T (2012) Critical materials and The Netherlands - a view from the industrialtechnological sector. Materials innovation institute (M2i) and Delft University of Technology. Accessible from http://www.criticalrawmaterials.eu/wp-content/uploads/Critical-materials-in-the-dutch-technologicalindustry-2012-M2i-TNO.pdf. 5 Aug 2017

10. CRM_Innonet Project (2015) Deliverable D8.1 Conclusions report. Accessible from http://www. criticalrawmaterials.eu/. 5 June 17

11. CRM_Innonet Project (2015) Deliverable D5.3 Final roadmap report. Accessible from http://www. criticalrawmaterials.eu/. 5 June 17

12. Peck D, Kandachar P, Tempelman E (2015) Critical materials from a product design perspective. Elsevier, Mater Des 65, p 147-159

13. Sundin E, Lee HM (2011) In what way is remanufacturing good for the environment? Proceedings of EcoDesign 2011 International Symposium

14. Lee HM, Sundin E, Nasr N (2011) Review of end-of-life management issues in sustainable electronic products. The 9th Global Conference on Sustainable Manufacturing

15. Sundin E, Lindahl M (2008) Rethinking design for remanufacturing to facilitate integrated product service offerings. Linköping University

16. Ijomah WL, McMahon CA, Hammond GP, Newman ST (2007) Development of robust design-forremanufacturing guidelines to further the aims of sustainable development. Int J Prod Res 45(18-19): 4513-4536. doi:10.1080/00207540701450138

17. Hatcher GD, Ijomah WL, Windmill JFC (2011) Design for remanufacture: a literature review and future research needs. Elsevier, J Clean Prod 19, p 2004-2014

18. Gray C, Charter M (2007) Remanufacturing and product design - designing for the 7th Generation. The Centre for Sustainable Design, University College for the Creative Arts, Farnham, UK

19. USITC (2012) Remanufactured goods: an overview of the US and global markets and trade. Accessible from http://www.usitc.gov/publications/332/pub4356.pdf. 5 June 17

20. Ellen MacArthur Foundation (2015) Delivering the circular economy: a toolkit for policymakers. V1.1. Accessible from https://www.ellenmacarthurfoundation.org/assets/downloads/publications /EllenMacArthurFoundation_PolicymakerToolkit.pdf. 5 June 17 